\title{
Microendoscopic Removal of Deep-Seated Brain Tumors Using Tubular Retraction System
}

\author{
Shailendra Ratre ${ }^{1}$ Yad Ram Yadav ${ }^{1}$ Vijay Singh Parihar ${ }^{1}$ Yatin Kher ${ }^{1}$ \\ 1 Department of Neurosurgery, NSCB Medical College Jabalpur, \\ Jabalpur, Madhya Pradesh, India \\ J Neurol Surg A 2016;77:312-320. \\ Address for correspondence Yad Ram Yadav, MCh, Department of \\ Neurosurgery, NSCB Medical College and Hospital, 105 Nehru Nagar \\ Opposite Medical College, Jabalpur, MP 482003, India \\ (e-mail: yadavyr@yahoo.co.in).
}

\begin{abstract}
Keywords

- brain retractors

- brain tumors

- minimally invasive surgical procedures

- neuroendoscopy

- tubular retractor system
\end{abstract}

Background Retraction of the overlying brain can be difficult without causing significant trauma when using traditional brain retractors with blades. These retractors may produce focal pressure and may result in brain contusion or infarction. Tubular retractors offer the advantage of low retracting pressure that is less likely to be traumatic. Low retraction pressure in the tubular retractor is due to the distribution of retraction force in all directions in a larger area.

Material and Methods We conducted a retrospective study of 100 patients with deepseated tumors operated on from January 2010 to December 2014. Tumor removal was accomplished with the help of a microscope and/or endoscope. Tubular brain retractors sizes 23,18 , and $15 \mathrm{~mm}$ were used. Folding of the tubular retractor after making a longitudinal cut allowed a small corticectomy. Larger retractor sizes were used in the earlier part of the study and in larger tumors. All the patients were evaluated postoperatively by computed tomography scan on the first postoperative day, and subsequent scans were done as and when needed. Any brain contusion or infarctions and the amount of tumor removal were recorded.

Results A total of 74 patients had astrocytomas; 12 , meningiomas; 4 , colloid cyst of the third ventricle; 4 , metastases; 4 , primitive neuroectodermal tumor; 1 , neurocytoma; and 1 , ependymoma. Pure endoscopic excision without using a microscope was performed in 12 patients. Lesions were in the frontal $(n=34)$, parietal $(n=22)$, intraventricular $(n=16)$, basal ganglion or thalamic $(n=14)$, occipital $(n=10)$, and cerebellar $(n=4)$ areas. Total, near-total, and partial excision was achieved in 49, 29, and 22 patients, respectively. Use of a conventional retractor for excision of peripheral and superficial parts of a large tumor, small brain contusions, and technical failure were observed in 7, 4, and 1 patient, respectively. The low incidence of contusion may be partly due to the nonavailability of magnetic resonance imaging in the early postoperative period because of financial constraints.

Conclusion Removal of deep-seated tumors was safe and effective using our simple tubular retractor. It also helped minimize bleeding during surgery. A tubular brain retractor and conventional retractor can be used to complement each other if required. received

July 27, 2015

accepted after revision

November 30, 2015

published online

April 11, 2016 (c) 2016 Georg Thieme Verlag KG

Stuttgart · New York
DOI http://dx.doi.org/ 10.1055/s-0036-1580595. ISSN 2193-6315. 


\section{Introduction}

Deep-seated intraparenchymal and intraventricular brain lesions require retraction of the overlying brain. This retraction can be difficult without causing significant trauma. Traditional brain retractors using blades produce focal pressure and thus are traumatic. ${ }^{1}$ Complications like hemorrhagic infarct or contusions are reported with the use of such retractors. ${ }^{2-5}$

Tubular retractors offer the advantage of low retracting pressure $^{1-4,6,7}$ that is unlikely to be disruptive. ${ }^{8}$ Low retraction pressure in our retractor system is due to an even distribution of retraction force in all directions over the larger area. Different types of tubular retractors are available including our own retractor. ${ }^{1,6-11}$ We report our experience in the excision of deep-seated tumors using a microendoscopic technique.

\section{Material and Methods}

This is a retrospective study of 100 patients with deep-seated tumors treated from January 2010 to December 2014. The ethics committee of our institution approved the study. Data regarding history, physical examination, and relevant investigations were obtained from patients' records. Preoperative

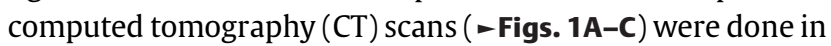
all patients, and a magnetic resonance imaging (MRI) scan ( - Figs. 2A-C, 3A-C) could only be performed in 81 patients after 6 weeks of surgery.

Tumor removal was done in the initial 15 patients using a microscope with the help of a $23-\mathrm{mm}$ tubular retractor.
Tubular brain retractor sizes of $18 \mathrm{~mm}$ and $15 \mathrm{~mm}$ were used in the following 85 patients, and procedures were performed with the help of a microscope and endoscope (Karl Storz, Tuttlingen, Germany), a 0-degree rigid scope $30 \mathrm{~cm}$ long and $4 \mathrm{~mm}$ in diameter. Larger retractor sizes were also required in bigger tumors. Larger size retractors provided more space to work when sufficient space was created after tumor removal in a big lesion. A larger size retractor tube was also better than a small one because the more space created after tumor removal tended to make the small size retractor unstable. In most of the patients, initial tumor excision was done with the help of a microscope; an endoscope was used for the final inspection and removal of lesions from corners. Pure endoscopic removal was done in 12 cases that were smaller and less vascular. All the patients were evaluated postoperatively by CT scan on the first postoperative day, and subsequent scans were done as and when needed and after 3 months (-Fig. 1D-F, 2D-F, 3D-F). MRI could not be done in the early postoperative period in any of the patients. Postoperative MRI scans were performed in only 81 patients 6 weeks after surgery due to financial constraints. Any brain contusion or infarctions and the amount of tumor removal were recorded.

\section{Surgical Procedure}

Details of the technique are described elsewhere. ${ }^{5} \mathrm{~A}$ straight incision of $6 \mathrm{~cm}$ was made under general anesthesia. The dura mater was opened in a circular fashion after reflecting the bone flap. The silicone tubular retractors were precut to different lengths of 5, 6, 7, and $8 \mathrm{~cm}$. A sterilized tube $\sim 30 \mathrm{~cm}$ long was
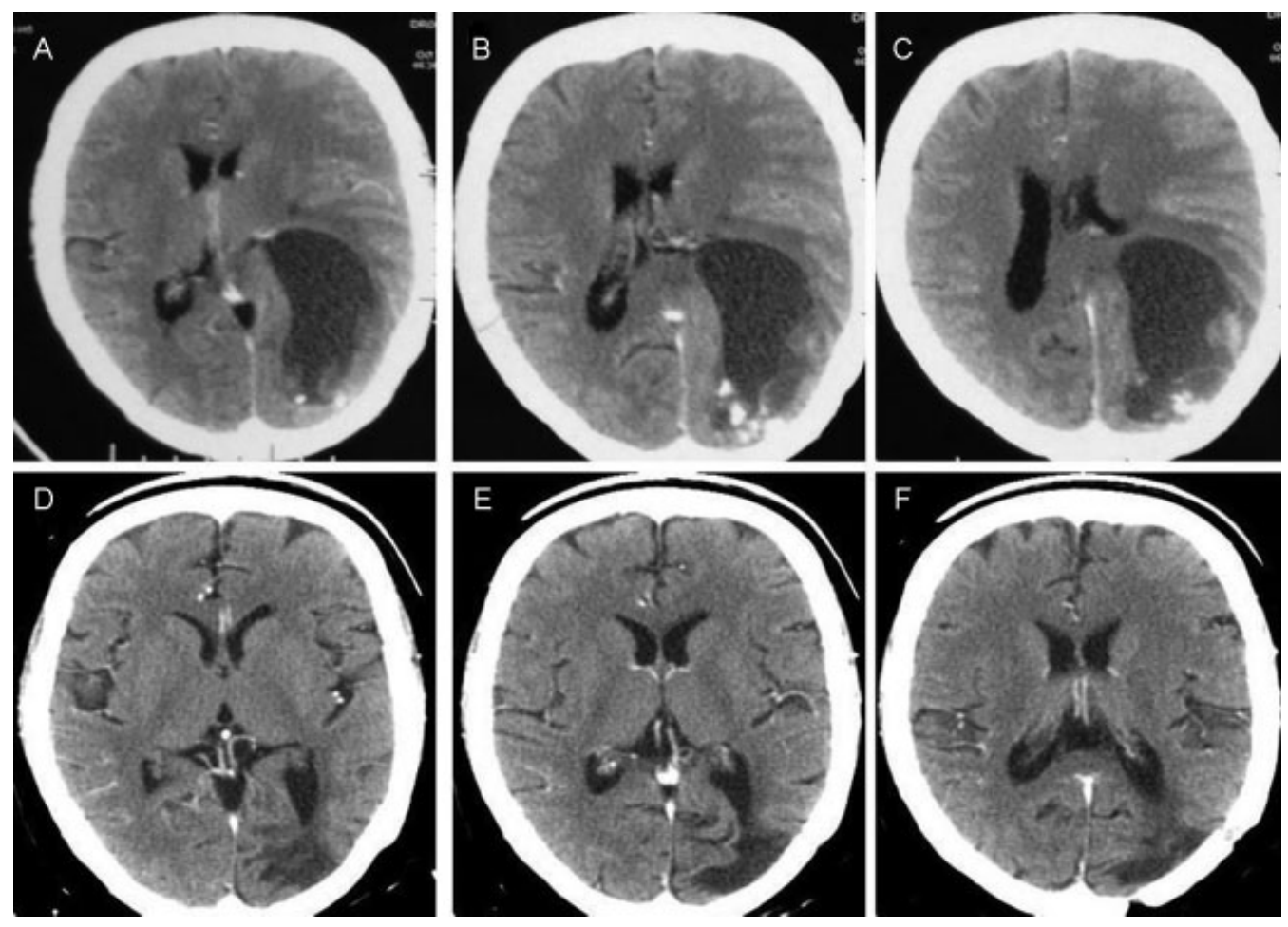

Fig. 1 (A-C) Preoperative computed tomography (CT) scan showing tumor in left occipital region pushing occipital horn anteriorly, and CT images (D-F) after tumor excision. 

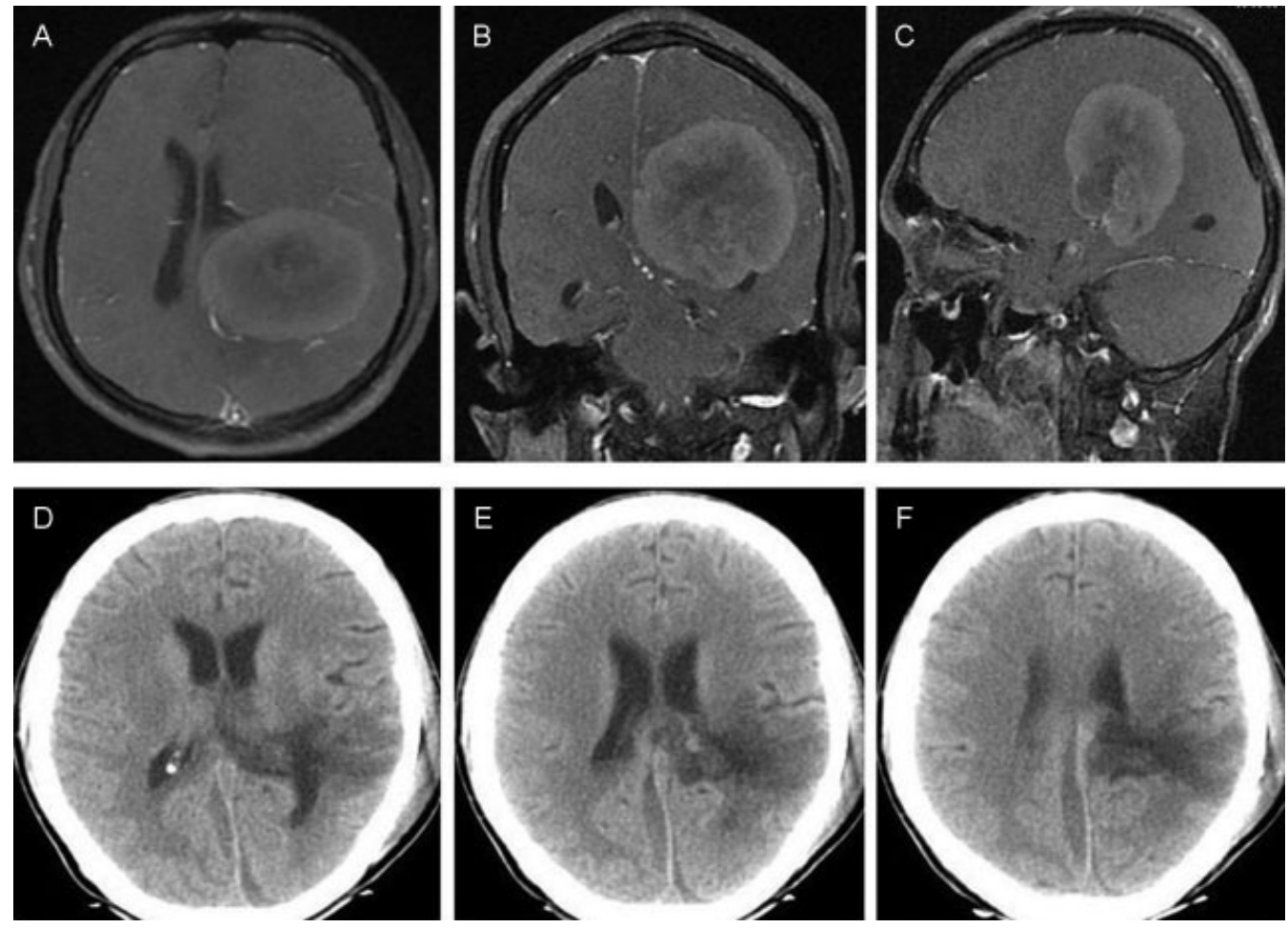

Fig. 2 (A-C) Preoperative magnetic resonance imaging scan showing large tumor near left atrium that was removed (D-F) using tubular retractor.
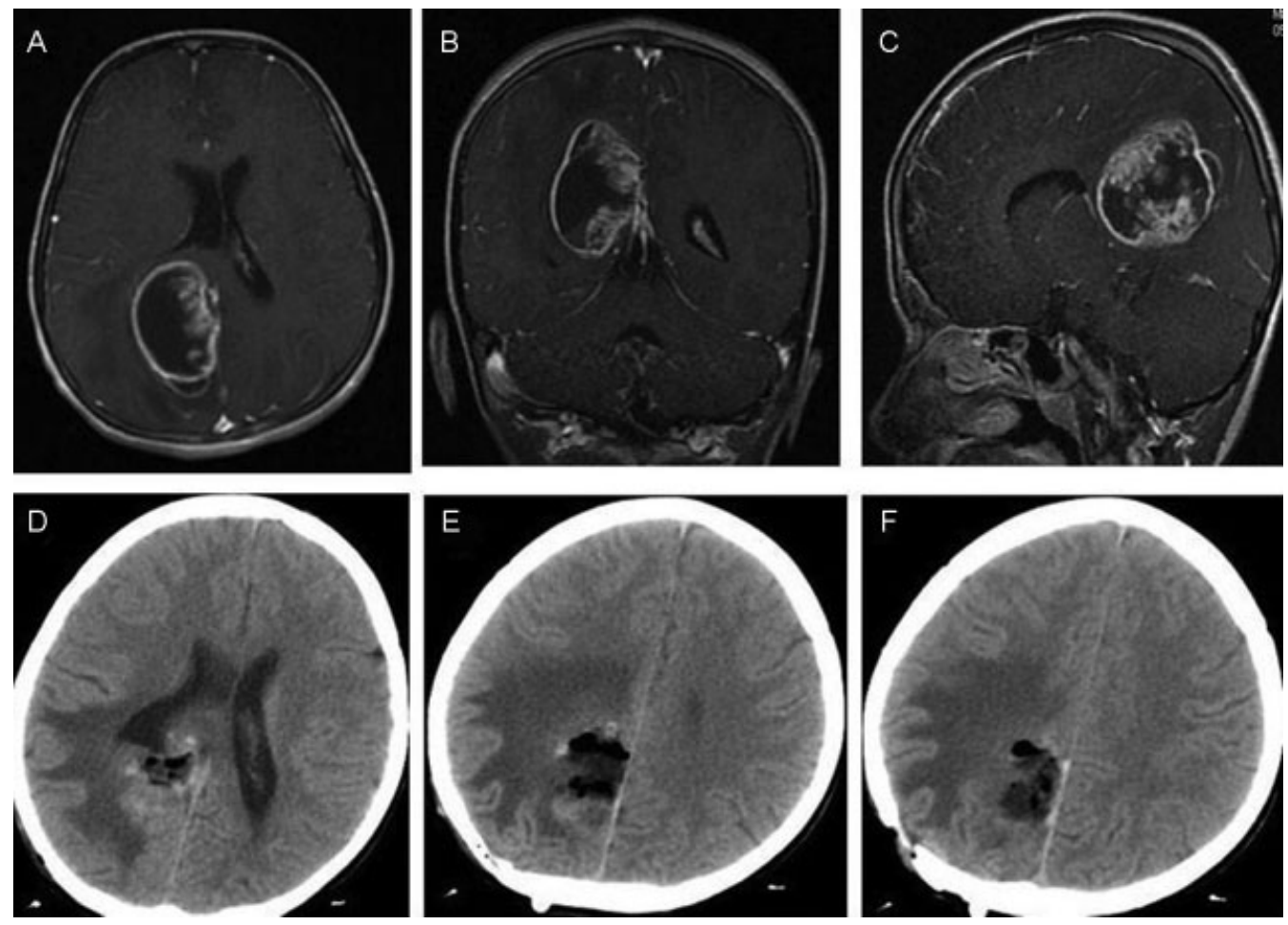

Fig. 3 (A-C) Preoperative magnetic resonance imaging scan showing tumor near right occipital horn and (D-F) computed tomography images after tumor excision. 
also kept ready, and it could be cut to the required size on the table. Silicone tubes of 15,18 , and $23 \mathrm{~mm}$ were used as a brain retractor. The tube used was $1 \mathrm{~mm}$ thick. It was cut in a longitudinal direction to allow folding. A small corticectomy of $5 \mathrm{~mm}$ was made to reach the tumor. Margins of the corticectomy were gently and slowly retracted using a Killian nasal speculum. The brain was made lax by removal of cerebrospinal fluid (CSF) before the introduction of the speculum.

The tubular retractor was folded to make a small-diameter tube so it could be introduced through a small corticectomy. Folded retractor, held by tissue forceps holding the free outer edge of the retractor (with one limb of the forceps outside and another inside the retractor) was introduced inside the opened Killian nasal speculum. ${ }^{5}$ Tissue forceps and nasal speculum were removed leaving the tubular retractor in place. The folded retractor comes back to its normal tubular position after release. Its normal tubular configuration can be restored by gentle outward pressure on the retractor with two micro-instruments such as a suction cannula and dissector. Surgery was performed using a microscope or a $30-\mathrm{cm}-$ long and 4-mm-diameter 0-degree telescope (Karl Storz) (-Figs. 4 and 5). A 30-cm-long scope versus an 18-cm-long scope keeps the camera head and light source cable away from the operative site. A telescope with its sheath was then fixed using a holder. Both hands could be used for removal of tumor with the help of a suction cannula, biopsy forceps, and other micro-instruments. Bipolar coagulation was done using a single-limb bipolar forceps. Most of the approaches were transcortical, interhemispheric route, or the access between dura matter and cortex was also used.

Proper selection of the site of incision is very important; the retractor should have $\sim 90$-degree angle with the floor of the operating room to work properly (-Fig. 6). Proper vision and good magnification were possible in all the cases. The brain should be lax before introduction of the nasal speculum by the removal of CSF to decrease brain damage, especially when the lesion is very large. Help from the anesthesiologist and removal of some part of the superficially lying tumor using a microsurgical technique could be required to make the brain lax, especially in large tumors before the introduction of the nasal speculum to avoid surrounding brain contusion.

A tubular retractor could be effective in reducing bleeding by gently pushing it deep into the operative field and by angling the tube toward the bleeding vessel ( - Fig. 7). Gently pushing the retractor deep and toward the bleeding vessel compresses the culprit vessels that helps minimize the
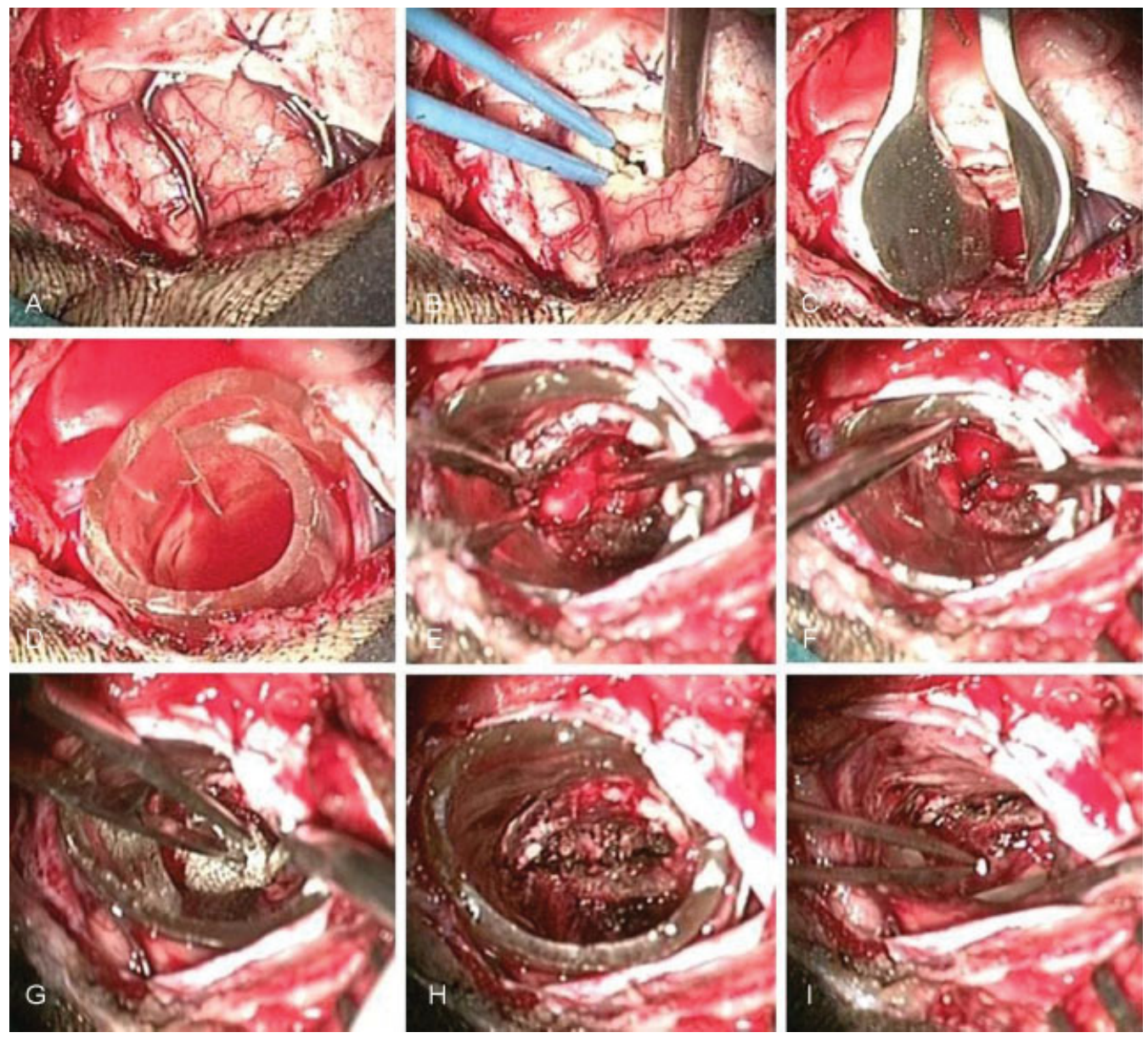

Fig. 4 Microscopic removal of tumor near atrium showing (A) dural incision, (B) small corticectomy, (C) introduction of nasal speculum, (D) position of tubular retractor, (E, F) removal of tumor using bimanual technique, and $(\mathrm{G}-\mathrm{I})$ hemostasis using absorbable hemostat. 

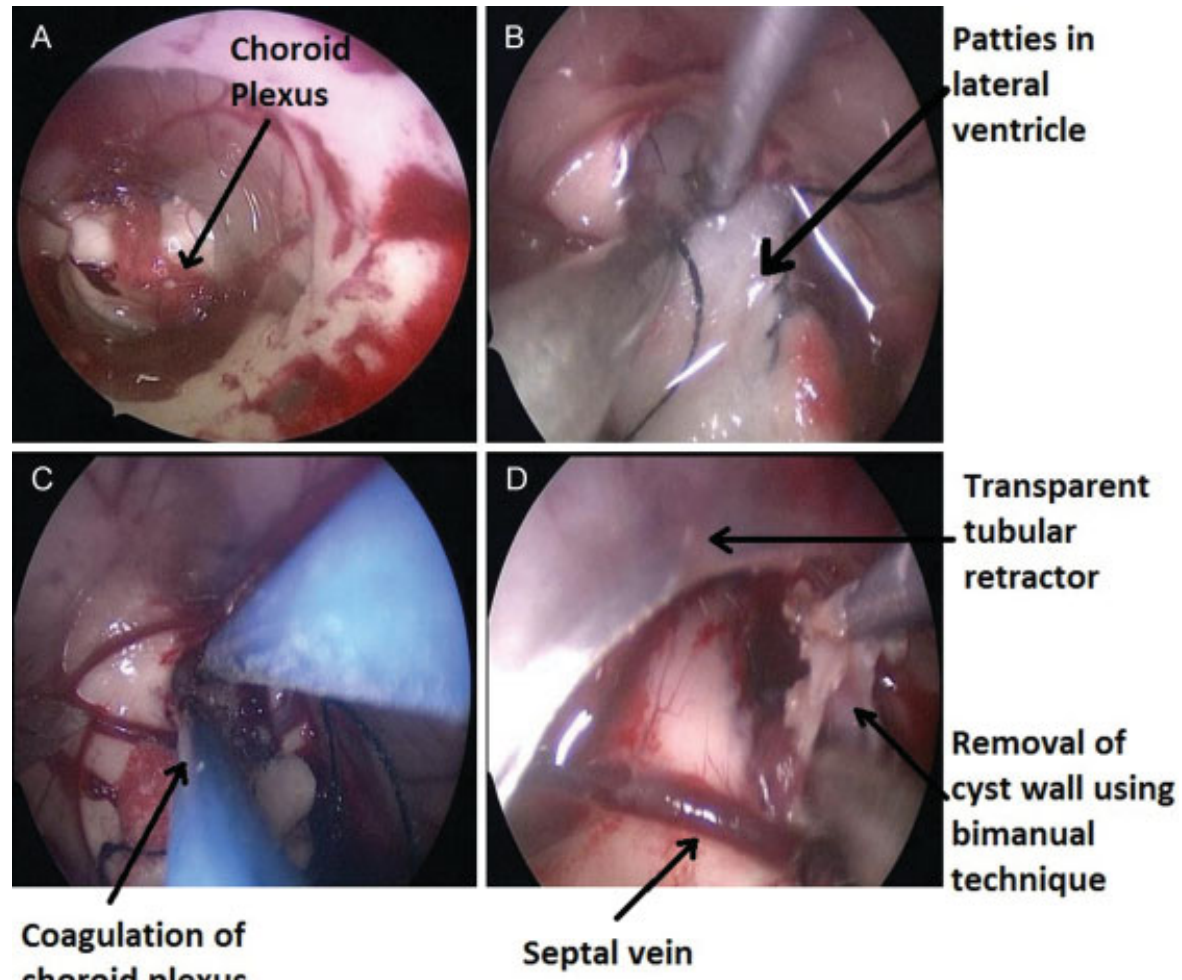

\section{Coagulation of choroid plexus and cyst wall}

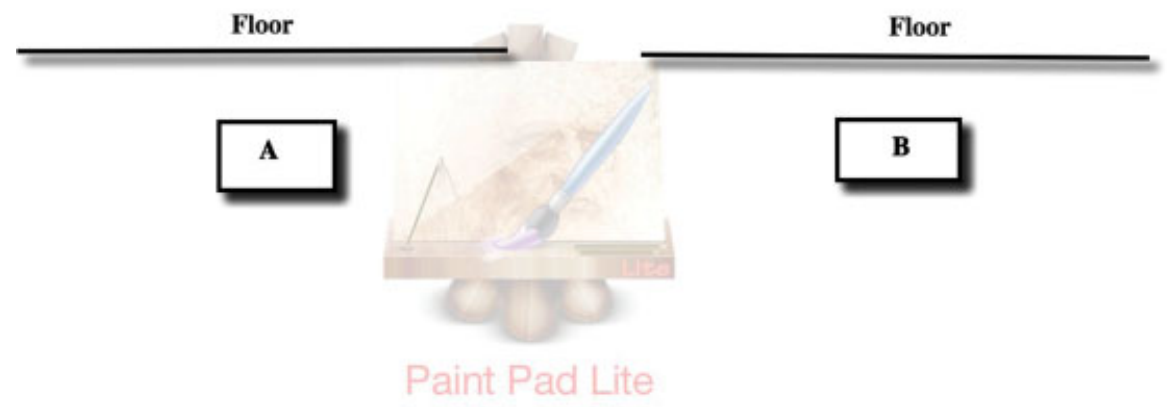

Fig. 6 (A) Proper trajectory of retractor with 90-degree angle with floor of operation is very important for the retractor to work properly. (B) It is difficult to maintain parallel orientation of the retractor to the floor. The overlying brain tends to cause pressure on the retractor, distorting its round shape and adding to the difficulty of the surgery. 

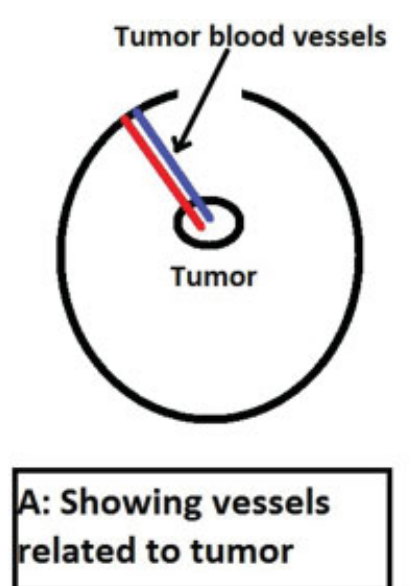

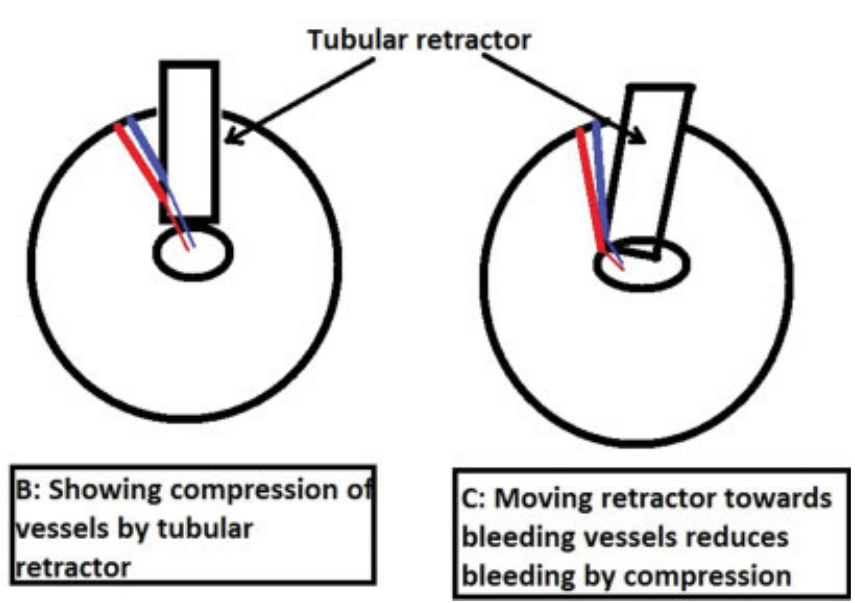

Fig. 7 (A) A tubular retractor is effective in reducing bleeding by gently pushing the retractor deep in the operative field and angling it toward the bleeding vessel (B). Pushing the retractor deep and toward the bleeding vessel (C) compresses the culprit vessel minimizing the bleeding.

bleeding. The tubular retractor usually stays in position without any holder, especially when it is held 90 degrees to the floor of the operating table. Some micro-instrument held by the surgeon or an assistant is required to angulate the retractor away from its trajectory. The retractor should be positioned correctly at the center of the tumor ( $\mathbf{F i g . 8 A}$ ). The surrounding brain tends to compress the wall of the retractor if the wrong trajectory at the margin of tumor is selected and an attempt is made to move the tube toward the center or other end of the tumor ( $\mathbf{- F i g . ~} \mathbf{8 B}$ ). It is difficult to access the whole area of a large tumor for its removal by the tubular retractor ( - Fig. 9). More angulation is required for removal of a large tumor from one end to other end, which is difficult to maintain; the surrounding brain tends to push the system (-Fig. 9B). Full-thickness tumor removal in front of the tubular retractor from a superficial to deep aspect permits

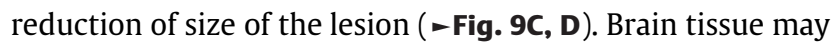
soil the endoscope lens if it is lying close to the cut part of the tubular retractor; rotation of the retractor prevents this

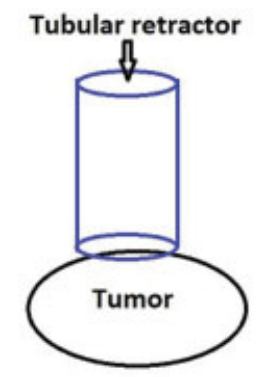

\section{A: Proper trajectory of retractor at center of tumor}

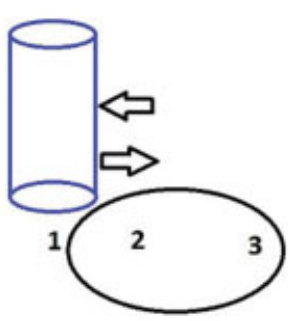

\section{B: Wrong trajectory at periphery of tumor}

Fig. 8 (A) Trajectory of the tubular retractor should be at the center of the tumor. (B) It is difficult to angulate the retractor tube (arrow to right) toward the center (position 2) and the other end (position 3) after wrong placement at the periphery of the lesion. The surrounding brain (arrow to left) tends to push the retractor back. soiling. It is important to realize that this system is meant for deep-seated lesions; the superficial part lying at the corner is difficult to remove because it needs too much angulation. Use of a conventional retractor could be required in such situations. Direction of light in the microscope and endoscope should be parallel to the retractor wall. The transparent nature of the tube helped better visualize the surrounding brain tissue. Bleeding from the corticectomy margin was controlled while the retractor was gradually withdrawn.

This retractor should be autoclaved. It could also be sterilized by activated dialdehyde solution (Cidex solution;

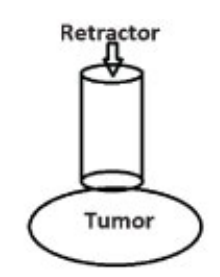

A: Large tumor with correct trajectory of retractor

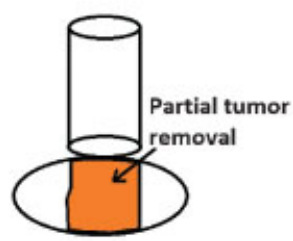

C: Tumor removal up to full depth in front of trajectory of the tubular retractor

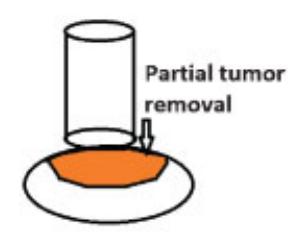

B: Partial removal of superfial part of tumor requires more

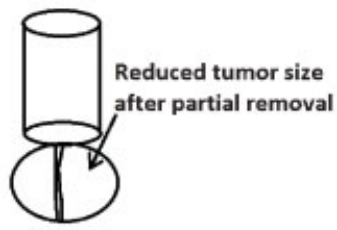

D: Reduced tumor size and difficult angulation of tube after partial excision

Fig. 9 (A) The retractor should be placed at the center of the tumor. (B) Angulation of the tube for removal of the full extent of the tumor from one end to other is difficult and requires more angulation. (C) Tumor removal up to full depth from the superficial to the deep part helps reduce tumor size (D), which can be removed easily because it is lying in front of the retractor. 
Johnson and Johnson New Brunswick, New Jersey, United States) or by ethylene oxide sterilization.

\section{Results}

Patients ranged from 2 to 76 years of age (68 male). There were 100 patients: astrocytoma $n=74$, meningiomas $n=12$, colloid cyst of third ventricle $n=4$, metastasis $n=4$, primitive neuroectodermal tumor $n=4$, neurocytoma $n=1$, and ependymoma $\mathrm{n}=1$. Pure endoscopic excision without using a microscope was performed in 12 patients (-Table 1). In 88 patients, the microscope was used for most of the tumor excision; the endoscope was used for the final inspection and removal of lesions in corners. Lesions were located in the frontal $(\mathrm{n}=37)$, parietal $(\mathrm{n}=22)$, intraventricular $(\mathrm{n}=16)$, basal ganglion and thalamic $(\mathrm{n}=11)$, occipital $(\mathrm{n}=10)$, and cerebel$\operatorname{lar}(\mathrm{n}=4)$ areas. Total, near-total, and partial excision was done in 49, 29, and 22 patients, respectively. The exact incidence of tumor resection could differ slightly because MRI scans could not be performed in all patients. Total excision was possible of all benign tumors. There was no infarction or infection. Brain contusions were observed in four patients.

Use of a conventional retractor for excision of parts lying superficially and peripherally was required in seven patients. MRI in the early postoperative period could not be performed in any of our patients due to financial constraints. The incidence of contusion may be higher than reported in our series because the CT scan is not as sensitive as MRI in the detection of small contusions. There was one technical failure in the initial period of the learning curve. The tubular retractor could not be used in this patient; a blade retractor was used for tumor excision. There was difficulty in maintaining the proper position of the tubular retractor. Tubular retractor was wrongly placed parallel to the operating room floor and was being compressed/distorted by the overlying brain. Blood loss during the whole procedure varied from 20 to $500 \mathrm{~mL}$ (average: $100 \mathrm{~mL}$ ).

\section{Discussion}

Expandable and nonexpandable tubular retractors have been used in various spinal techniques. ${ }^{12-14}$ They were used for foraminotomy, diskectomy, lumbar lesions, thoracic pathologies, cervical myelopathy, spinal fusion, spinal infections, and for dural closure in intradural spinal pathology. They were also used for single-, two-, and multiple-level pathologies. Tubular retractors have been used in various cranial approaches such as intracranial hematomas, ${ }^{5}$ cranial tumors, ${ }^{11,15-20}$ colloid cyst, ${ }^{21,22}$ arteriovenous malformation, ${ }^{1}$ and for cavernous malformation. ${ }^{23}$ Three-dimensional endoscopic visualization ${ }^{24}$ and frameless stereotactic techniques ${ }^{6}$ can be combined with the tubular retractor system for deep brain lesions.

The tubular retractor was found to be safe in our study. Other authors made similar observations. ${ }^{11,15,19,23-25}$ It was effective in our series and in other reported series. ${ }^{18,19}$ Tubular retractors provided excellent visualization of the underlying pathology and facilitated tumor removal and dissection resulting in $49 \%$ total and $29 \%$ near-total removal of tumor in our study. It allowed rotation of the tubular retractor and some change in the angle of approach without putting extra pressure on the brain tissue, which usually occurs when malleable or other ribbon-type retractors are used. $^{25}$ Tubular retractors were also effective in reducing bleeding by gently pushing the retractor deep in the operative field and by angling it toward the bleeding vessel. Our average blood loss was $100 \mathrm{~mL}$. Similar advantages of helping in hemostasis were reported by Herrera et al. ${ }^{25}$ Tubular retractors have been found to reduce postoperative wound infections significantly, as much as 10 -fold compared with open spinal surgery. ${ }^{26,27}$ The minimally invasive nature of the procedure reduced the risk of postoperative infection in spine surgeries. $^{28}$

Advantage of our retractor is that a small corticectomy is required due to a longitudinal cut and folding technique of the retractor. It is transparent, lightweight, and versatile, can be moved in any direction, avoids time wasted in repositioning, and a holder is not required. The technique is simple, safe, inexpensive, and effective. One can use microscope or endoscope as needed. This tubular retractor system is readily available. Tubular retractor also helps reduce bleeding (-Fig. 7). Although we had four small contusions in our series, the soft and malleable tube usually helps prevent

Table 1 Patient characteristics

\begin{tabular}{|l|l|}
\hline Age, $\mathbf{y}$ & $2-76$ \\
\hline Sex & 68 male patients \\
\hline Pathologic type of tumor $(\mathbf{n})$ & $\begin{array}{l}\text { Astrocytoma (74), meningiomas (12), colloid cyst of third ventricle (4), metastasis (4), } \\
\text { primitive neuroectodermal tumor (4), neurocytoma (1), ependymoma (1) }\end{array}$ \\
\hline Type of surgery & Pure endoscopic in 12 cases; microscopic and endoscopic in 88 patients \\
\hline Location ( $\mathbf{n})$ & $\begin{array}{l}\text { Frontal (37), parietal (22), intraventricular (16), basal ganglion and thalamic (11), } \\
\text { occipital (10), and cerebellar (4) }\end{array}$ \\
\hline No. of tumor excisions & Total or near-total excision in 78 patients and subtotal in 22 patients \\
\hline Complications & Four small contusions and one technical failure \\
\hline Blood loss & Blood loss varied from $20 \mathrm{~mL}$ to $500 \mathrm{~mL}$ (average: $100 \mathrm{~mL})$ \\
\hline
\end{tabular}


brain damage. These contusions were in large tumors, and the brain could not be properly relaxed before introducing the speculum. Similar results of reduced brain retraction-related injuries were reported. ${ }^{6,15,20,25}$

The technique discussed in this study was also associated with some limitations. There was one technical failure in the beginning of our learning curve due to incorrect planning of patient position. It was difficult to maintain retractor position, and there was distortion of the shape of the retractor by pressure from the surrounding brain. It is difficult to remove peripheral and superficial part of a large tumor with a tubular retractor as mentioned earlier; use of a conventional retractor could be required in such situations. The tubular retractor system, conventional blade retractor system, and retraction with the help of micro-instruments can be used for patient benefit. The retractor should be nearly perpendicular to the floor of the operating room to allow proper retraction. It is difficult to maintain parallel orientation of retractor to the floor. The overlying brain tends to cause pressure on the wall of the retractor, distorting its round shape and thus adding to the difficulty of surgery (-Fig. 6). Total tumor removal may be difficult especially in large tumors (-Fig. 9) and calcified tumors in the beginning of the learning curve. ${ }^{16}$ Proper case selection, especially at the beginning of the learning curve, is required. We performed hematoma removal in the beginning of our learning curve, and only after removal of 50 hematomas did we start tumor excision. Proper planning about the site of skin incision and patient positioning is very important (-Fig. 6). This procedure is associated with a steep learning curve, which is commonly observed in most endoscopic procedures. ${ }^{29-31}$ Surgeon should practice this procedure in the laboratory to avoid complications. Exact incidence of postoperative contusion could be higher due to the nonavailability of MRI in the early postoperative period. Nasal speculum opening (even if slow and gentle) may produce contusion in a tight brain especially in a large tumor. Every attempt must be made to make the brain lax before introduction of the speculum to avoid contusion. Likewise, the incidence of tumor excision could be different as postoperative MRI could be performed in $81 \%$ of patients. There is no holder in this system; one micro-instrument, held by the surgeon or assistant, is required to maintain that angulated position.

A pen-type grip and well-supported hand on the operative site is helpful to improve precision. ${ }^{32-34}$ Single-shaft instruments are preferred rather than double-shaft instruments because they occupy less space. ${ }^{34}$ The endoscope must be positioned properly in an already limited space. The scope may obstruct movement of the instruments. ${ }^{32}$

\section{References}

1 Fahim DK, Relyea K, Nayar VV, et al. Transtubular microendoscopic approach for resection of a choroidal arteriovenous malformation. J Neurosurg Pediatr 2009;3(2):101-104

2 Rosenørn J, Diemer N. The risk of cerebral damage during graded brain retractor pressure in the rat. J Neurosurg 1985;63(4): 608-611
3 Singh L, Agrawal N. Stitch retractor-simple and easy technique to retract brain. World Neurosurg 2010;73(2):123-127

4 Thiex R, Hans FJ, Krings T, Sellhaus B, Gilsbach JM. Technical pitfalls in a porcine brain retraction model. The impact of brain spatula on the retracted brain tissue in a porcine model: a feasibility study and its technical pitfalls. Neuroradiology 2005;47(10):765-773

5 Yadav YR, Yadav S, Sherekar S, Parihar V. A new minimally invasive tubular brain retractor system for surgery of deep intracerebral hematoma. Neurol India 2011;59(1):74-77

6 Greenfield JP, Cobb WS, Tsouris AJ, Schwartz TH. Stereotactic minimally invasive tubular retractor system for deep brain lesions. Neurosurgery 2008;63(4, Suppl 2):334-339, discussion 339-340

7 Singh L, Agrawal N. Cylindrical channel retractor for intraventricular tumour surgery-a simple and inexpensive device. Acta Neurochir (Wien) 2009;151(11):1493-1497

8 Ogura K, Tachibana E, Aoshima C, Sumitomo M. New microsurgical technique for intraparenchymal lesions of the brain: transcylinder approach. Acta Neurochir (Wien) 2006;148(7):779-785; discussion 785

9 Cabbell KL, Ross DA. Stereotactic microsurgical craniotomy for the treatment of third ventricular colloid cysts. Neurosurgery 1996; 38(2):301-307

10 Ross DA. A simple stereotactic retractor for use with the Leksell stereotactic system. Neurosurgery 1993;32(3):475-476; discussion 476

11 Ichinose T, Goto T, Morisako H, Takami T, Ohata K. Microroll retractor for surgical resection of brainstem cavernomas. World Neurosurg 2010;73(5):520-522

12 Tan LA, O'Toole JE. Tubular retractor selection in minimally invasive spinal tumor resection. J Neurosurg Spine 2014;20(5): 596-597; author reply 597-598

13 Hur JW, Kim JS, Shin MH, Ryu KS. Minimally invasive posterior cervical decompression using tubular retractor: the technical note and early clinical outcome. Surg Neurol Int 2014;5:34

14 Dong J, Rong L, Feng F, et al. Unilateral pedicle screw fixation through a tubular retractor via the Wiltse approach compared with conventional bilateral pedicle screw fixation for singlesegment degenerative lumbar instability: a prospective randomized study. J Neurosurg Spine 2014;20(1):53-59

15 Recinos PF, Raza SM, Jallo GI, Recinos VR. Use of a minimally invasive tubular retraction system for deep-seated tumors in pediatric patients. J Neurosurg Pediatr 2011;7(5):516-521

16 Jo KW, Shin HJ, Nam DH, et al. Efficacy of endoport-guided endoscopic resection for deep-seated brain lesions. Neurosurg Rev 2011;34(4):457-463

17 Raza SM, Recinos PF, Avendano J, Adams H, Jallo GI, QuinonesHinojosa A. Minimally invasive trans-portal resection of deep intracranial lesions. Minim Invasive Neurosurg 2011;54(1):5-11

18 Jo KI, Chung SB, Jo KW, Kong DS, Seol HJ, Shin HJ. Microsurgical resection of deep-seated lesions using transparent tubular retractor: pediatric case series. Childs Nerv Syst 2011;27(11): 1989-1994

19 Almenawer SA, Crevier L, Murty N, Kassam A, Reddy K. Minimal access to deep intracranial lesions using a serial dilatation technique: case-series and review of brain tubular retractor systems. Neurosurg Rev 2013;36(2):321-329; discussion 329-330

20 Bernardo A, Evins AI, Tsiouris AJ, Stieg PE. A percutaneous transtubular middle fossa approach for intracanalicular tumors. World Neurosurg 2015;84(1):132-146

21 Cohen-Gadol AA. Minitubular transcortical microsurgical approach for gross total resection of third ventricular colloid cysts: technique and assessment. World Neurosurg 2013;79(1):207. e7-207.e10

22 Ajlan AM, Kalani MA, Harsh GR. Endoscopic transtubular resection of a colloid cyst. Neurosciences (Riyadh) 2014;19(1):43-46

23 Noh JH, Cho KR, Yeon JY, Seol HJ, Shin HJ. Microsurgical treatment and outcome of pediatric supratentorial cerebral cavernous malformation. J Korean Neurosurg Soc 2014;56(3):237-242 
24 Shoakazemi A, Evins AI, Burrell JC, Stieg PE, Bernardo A. A 3D endoscopic transtubular transcallosal approach to the third ventricle. J Neurosurg 2015;122(3):564-573

25 Herrera SR, Shin JH, Chan M, Kouloumberis P, Goellner E, Slavin KV. Use of transparent plastic tubular retractor in surgery for deep brain lesions: a case series. Surg Technol Int 2010;19:47-50

26 O'Toole JE, Eichholz KM, Fessler RG. Surgical site infection rates after minimally invasive spinal surgery. J Neurosurg Spine 2009; 11(4):471-476

27 Ee WW, Lau WL, Yeo W, Von Bing Y, Yue WM. Does minimally invasive surgery have a lower risk of surgical site infections compared with open spinal surgery? Clin Orthop Relat Res 2014;472(6):1718-1724

28 Shousha M, Cirovic D, Boehm H. Infection rate after minimally invasive noninstrumented spinal surgery based on 4350 procedures. Spine 2015;40(3):201-205

29 Yadav YR, Madhariya SN, Parihar VS, Namdev H, Bhatele PR. Endoscopic transoral excision of odontoid process in irreducible atlantoaxial dislocation: our experience of 34 patients. J Neurol Surg A Cent Eur Neurosurg 2013;74(3):162-167

30 Yadav YR, Parihar V, Namdev H, Agarwal M, Bhatele PR. Endoscopic interlaminar management of lumbar disc disease. J Neurol Surg A Cent Eur Neurosurg 2013;74(2):77-81

31 Yadav YR, Parihar V, Pande S, Namdev H. Endoscopic management of colloid cysts. J Neurol Surg A Cent Eur Neurosurg 2014;75(5): 376-380

32 Yadav YR, Parihar V, Kher Y. Complication avoidance and its management in endoscopic neurosurgery. Neurol India 2013; 61(3):217-225

33 Yadav YR, Parihar V, Ratre S, Kher Y. Complication avoidance in endoscopic third ventriculostomy and its managements. J Neurol Surg A Cent Eur Neurosurg 2015; July 4 (Epub ahead of print)

34 Yadav YR, Parihar V, Ratre S, Kher Y, Iqbal M. Microneurosurgical skills training. J Neurol Surg A Cent Eur Neurosurg 2015; April 27 (Epub ahead of print) 